\title{
Alcohol Consumption and Risk of Type 2 Diabetes in Mongolian Population, Inner Mongolia, China
}

\author{
Hongmei $\mathrm{Li}^{1}$, Guiyan Wang ${ }^{1,2}$, Aili Wang ${ }^{1}$, Weijun Tong ${ }^{1}$ and Yonghong Zhang ${ }^{1 *}$ \\ ${ }^{1}$ Department of Epidemiology, School of Radiation Medicine and Public Health, Medical College of Soochow University, Suzhou, China \\ ${ }^{2}$ Department of Health Care, Xiamen Maternal and Child Care Hospital, Xiamen, China
}

\begin{abstract}
Aim: To investigate the association between alcohol consumption and risk of type 2 diabetes in the Mongolian population, China

Methods: Data on demographic, lifestyle factors, family history of hypertension, blood pressure and fasting blood glucose for 2563 Mongolians aged 20 years or older were collected, and associations between drinking and risk of impaired fasting glucose and type 2 diabetes were analyzed by multinomial logistic regression.

Results: Age-gender-adjusted Proportions of type 2 diabetes were significantly lower in subjects drinking $\leq 25 \mathrm{~g}$ and 26-50 $\mathrm{g}$ alcohol per day than those in both non-drinkers and $>50 \mathrm{~g}$ alcohol per day $(1.21 \%, 0.31 \%, 4.31 \%$ and $6.23 \%$, respectively), and multivariate adjusted odds ratio of type 2 diabetes associated with drinking $26-50 \mathrm{~g}$ alcohol per day was 0.11 (95\% confidence interval: $0.01-0.84$ ) compared to non-drinkers, but odds ratio for drinking $>50 \mathrm{~g}$ alcohol per day was not significant.
\end{abstract}

Conclusions: Drinking 26-50 g alcohol per day was associated with reduced risk of type 2 diabetes among the Mongolian population.

Keywords: Alcohol consumption; Type 2 diabetes; Mongolian population

\section{Introduction}

Heavy alcohol intake increases the risk of hypertension and cardiovascular disease [1-4], but the relationship between alcohol consumption and type 2 diabetes remains controversial. The inverse association between light to moderate alcohol consumption and type 2 diabetes has been observed by several studies [5-7]. While some studies suggested no association between alcohol intakes and type 2 diabetes $[8,9]$; other studies have shown that heavy drinking can increase blood glucose level or risk of type 2 diabetes [10,11].

In China, type 2 diabetes has become a major public health problem, and there were marked geographical and rural-urban difference in the prevalence of diabetes $[12,13]$. Mongolian is a minority living in the north of China. Most of them live as farmers and herders and maintain their traditional manner and custom of Mongolian ethnicity, which differ from Chinese Han people. Our previous study showed that the Mongolian population had higher prevalence of alcohol drinking and hypertension and there was a significant association between alcohol drinking and hypertension [14]. However, there are no reports on relationship between alcohol drinking and type 2 diabetes in the population. In the present study, we examined the association between alcohol drinking and type 2 diabetes among the Mongolian population, China.

\section{Methods}

\section{Study participants}

A cross-sectional survey was performed in a rural population of 32 villages in two townships, Kezuohou Banner (county) and Naiman Banner, Inner Mongolia, China, from July 2002 to September 2003. The two adjacent townships are $100 \mathrm{~km}$ from Tongliao, a prefecture level city in eastern Inner Mongolia, China. Most of the residents in the investigation field are Mongolian who had lived there for a long time from generation to generation. There were a total of 3475 Mongolian people aged 20 and older in the 32 villages. Among them, 2589 people signed informed consent, and their blood samples were collected and investigated in the field. A total of 886 did not sign informed consent and were not investigated because they were out of the field or refused to respond at the time of investigation. This study was approved by Sochoow University School of Radiation Medicine and Public Health Ethics Committee.

\section{Data collection and examination}

Data on demographic characteristics, lifestyle risk factors including cigarette smoking and alcohol drinking, family history of hypertension and histories of hypertension, cardiovascular and diabetes were obtained using a standard questionnaire administered by trained staffs. Cigarette smoking was defined as having smoked at least one cigarette per day for 1 year or more. The data on whether drinking or not, average quantity of drinking distillate spirit per day and number of years of drinking were collected according to study protocol ( the distillate spirit contain about $50 \%$ alcohol, namely $1 \mathrm{~g}$ distillate spirit is approximately $0.5 \mathrm{~g}$ alcohol ).

Three blood pressure (BP) measurements were performed by four trained doctors using a standard mercury sphygmomanometer and the

*Corresponding authors: Yonghong Zhang, MD, PhD, Department of Epidemiology, School of Radiation Medicine and Public Health, Medical College of Soochow University, 199 Renai Road, Industrial Park District, Suzhou, China, Tel: 086-512-65880078; E-mail: yhzhang@suda.edu.cn

Received November 17, 2010; Accepted January 01, 2011; Published January 04, 2011

Citation: Li H, Wang G, Wang A, Tong W, Zhang Y (2011) Alcohol Consumption and Risk of Type 2 Diabetes in Mongolian Population, Inner Mongolia, China. J Diabet Metabol 2:116. doi:10.4172/2155-6156.1000116

Copyright: @ $2011 \mathrm{Li} \mathrm{H}$, et al. This is an open-access article distributed unde the terms of the Creative Commons Attribution License, which permits unrestricted use, distribution, and reproduction in any medium, provided the original author and source are credited. 
Citation: Li H, Wang G, Wang A, Tong W, Zhang Y (2011) Alcohol Consumption and Risk of Type 2 Diabetes in Mongolian Population, Inner Mongolia, China. J Diabetes Metab 2:116. doi:10.4172/2155-6156.1000116

Page 2 of 5

mean of three BP measurements was used in the analysis. Hypertension was defined as systolic BP (SBP) $\geq 140$ and/or diastolic BP (DBP) $\geq 90$ $\mathrm{mmHg}$ and/or use of antihypertensive medication in recent 2 weeks. Body weight and height were measured with subjects wearing light clothing and without shoes by trained staff. The body mass index (BMI) was calculated as weight in kilograms divided by the square of the height in meters. The waist circumference (WC) was measured at the level of $1 \mathrm{~cm}$ above the umbilicus. The overweight was defined as BMI $\geq 25 \mathrm{~kg} / \mathrm{m}^{2}$, and central obesity was defined as WC $\geq 85 \mathrm{~cm}$ for male and $\geq 80 \mathrm{~cm}$ for female [15].

Fasting blood samples were collected in the morning after at least 8 $\mathrm{h}$ of fasting for all participants. Serum was subsequently isolated from the whole blood, and all serum samples were frozen at $-80{ }^{\circ} \mathrm{C}$ until testing. Fasting plasma glucose(FPG) was measured using a modified hexokinase enzymatic method. Cases of type 2 diabetes were identified by self-report and diagnostic laboratory test results, and diabetes treatment. The diagnosis was confirmed if participants reported at least one of the following on the questionnaire: treatment with either insulin or an oral hypoglycemic agent, or FPG $\geq 126 \mathrm{mg} / \mathrm{dl}(7.0 \mathrm{mmol} / \mathrm{L})$. Futhermore, impaired fasting glucose (IFG)was defined as $126 \mathrm{mg} /$ $\mathrm{dl}>\mathrm{FPG} \geq 110 \mathrm{mg} / \mathrm{dl}(6.1 \mathrm{mmol} / \mathrm{L})$, according to China Guideline for type 2 diabetes and impaired fasting glucose (2007 Edition) [16]. Concentrations of total cholesterol(TC), high-density lipoproteincholesterol(HDL-C), and triglycerides(TG) were assessed enzymatically on a Beckman Synchrony CX5 Delta Clinical System (Beckman Coulter, Fullerton, CA, USA) using commercial reagents, and lowdensity liporotein-cholesterol (LDL-C)concentration was calculated by means of the Friedewald equation for participants who had less than
$400 \mathrm{mg} / \mathrm{dL}$ triglycerides [17]. High triglycerides was defined as TG $\geq 1.70 \mathrm{mmol} / \mathrm{L}$, and high total cholesterol as TC $\geq 5.18 \mathrm{mmol} / \mathrm{L}$, high low-density liporotein-cholesterol as LDL-C $\geq 3.37 \mathrm{mmol} / \mathrm{L}$, low highdensity lipoprotein-cholesterol as $\mathrm{HDL}-\mathrm{C}<1.04 \mathrm{mmol} / \mathrm{L}$. C-reactive protein (CRP) was determined with immunoturbidimetry (ITM) on a Beckman Synchron CX5 Delta Clinical System using commercial reagents, high CRP was defined as $\mathrm{CRP} \geq 11.36 \mathrm{mg} / \mathrm{L}$ (the highest quartile).

\section{Statistical analysis}

The subjects were categorized into four groups based upon amount of alcohol consumption: non-drinkers, the subjects drinking $\leq 25$ g, 26-50 g, $>50 \mathrm{~g}$ alcohol per day. The means (standard deviations) or medians (quartile intervals range) of continuous variables were calculated for the four groups, respectively. Comparisons of means and medians among groups were conducted using analysis of variance (ANOVA) or Kruskal-Wallis rank test, and Student-Newman-Keuls (SNK) or Nemenyi rank tests were used for comparison between each two groups. Proportions and 95\% confidence intervals (95\%CI) for categorical variables were calculated and $\chi^{2}$ tests were performed to compare between/among groups.

Age and gender-adjusted proportions of diabetes and IFG were computed using a direct standardized method and compared using weighted $\chi^{2}$ tests. Associations between alcohol drinking and diabetes and IFG were analyzed using a logistic regression model. Quadratic trend test was conducted for relationship between alcohol and odds ratio(OR) of diabetes and IFG. All $P$-values were based on two-sides

\begin{tabular}{|c|c|c|c|c|}
\hline \multirow{2}{*}{ variables } & \multicolumn{4}{|l|}{ alcohol drinking status } \\
\hline & Non-drinking $(n=1707)$ & $\leq 25 \mathrm{~g} /$ day $(n=84)$ & $26-50 \mathrm{~g} /$ day $(n=176)$ & $>50 \mathrm{~g} /$ day $(n=596)$ \\
\hline Age(year) & $45.1 \pm 12.4$ & $50.0 \pm 14.3^{\dagger}$ & $49.8 \pm 12.3^{\dagger}$ & $49.2 \pm 11.3^{\dagger}$ \\
\hline Male $\%(95 \% \mathrm{Cl})$ & $21.7(19.8-23.8)$ & $48.8(37.9-60.0)^{\dagger}$ & $56.3(48.6-63.7)^{\dagger}$ & $90.4(87.8-92.7)^{\dagger \ddagger \Delta}$ \\
\hline Smoking. $\%(95 \% \mathrm{Cl})$ & $31.3(29.1-33.5)$ & $48.8(37.9-60.0)^{\dagger}$ & $68.8(61.3-75.5)^{\dagger \ddagger}$ & $74.7(71.0-78.1)^{\dagger \ddagger \Delta}$ \\
\hline Body mass index $\left(\mathrm{kg} / \mathrm{m}^{2}\right)^{\star}$ & $21.9(19.9-24.5)$ & $21.8(19.9-25.0)$ & $21.5(19.4-23.9)$ & $21.2(19.6-23.6)^{\dagger}$ \\
\hline Overweight(BMI $\left.\geq 25 \mathrm{~kg} / \mathrm{m}^{2}\right), \%(95 \% \mathrm{Cl})$ & $22.0(20.0-24.0)$ & $25.0(16.2-35.6)$ & $17.6(12.3-24.1)$ & $15.4(12.7-18.6)^{\dagger}$ \\
\hline Waist circumference $(\mathrm{cm})^{*}$ & 79(73-86) & $81(75-89)$ & $80(75-88)$ & $80(76-88)$ \\
\hline Central obesity. $\%(95 \% \mathrm{Cl})$ & $43.2(40.8-45.6)$ & $47.6(36.6-58.8)$ & $38.6(31.4-46.3)$ & $36.6(32.7-40.6)^{\dagger}$ \\
\hline Triglycerides $(\mathrm{mmol} / \mathrm{L}) *$ & $0.9(0.6-1.3)$ & $0.9(0.7-1.5)$ & $1.0(0.7-1.5)^{\dagger}$ & $1.1(0.7-2.0)^{\dagger \ddagger}$ \\
\hline Total cholesterol $(\mathrm{mmol} / \mathrm{L}){ }^{*}$ & $3.5(2.9-4.3)$ & $3.7(3.0-4.8)$ & $3.8(3.2-4.5)^{\dagger}$ & $3.7(3.1-4.6)^{\dagger}$ \\
\hline LDL-cholesterol (mmol/L) & $2.2(1.6-2.8)$ & $2.3(1.7-3.1)$ & $2.2(1.7-2.9)$ & $2.2(1.6-2.9)$ \\
\hline $\mathrm{HDL}-$ cholesterol $(\mathrm{mmol} / \mathrm{L})$ & $1.2 \pm 0.3$ & 1.20 .3 & $1.2 \pm 0.4$ & $1.2 \pm 0.3$ \\
\hline High triglycerides, $\%(95 \% \mathrm{Cl})$ & $12.3(10.8-14.0)$ & $20.5(12.4-30.8)$ & $20.1(14.4-26.8)^{\dagger}$ & $31.1(27.4-35.0)^{\dagger \Delta}$ \\
\hline High total cholesterol, $\%(95 \% \mathrm{Cl})$ & $8.3(7.1-9.7)$ & $14.6(7.8-24.2)$ & $12.1(7.6-17.9)$ & $14.4(11.6-17.5)^{\dagger}$ \\
\hline High LDL-cholesterol, \% $(95 \% \mathrm{Cl})$ & $12.6(11.1-14.3)$ & $21.9(13.6-32.5)$ & $14.5(9.6-20.6)$ & $16.3(13.4-19.5)$ \\
\hline Low LDL-cholesterol,\% (95\%Cl) & $38.4(36.1-40.8)$ & $40.2(29.6-51.7)$ & $35.3(28.2-42.9)$ & $34.1(30.2-38.0)$ \\
\hline Systolic $\mathrm{BP}(\mathrm{mmHg})^{*}$ & $120(110-137)$ & $130(114-141)^{\dagger}$ & $127(119-144)^{\dagger}$ & $130(120-148)^{\dagger}$ \\
\hline Diastolic $\mathrm{BP}(\mathrm{mmHg})^{*}$ & $80(74-90)$ & $82(79-91)$ & $85(80-95)^{\dagger}$ & $88(80-99)^{\dagger \ddagger}$ \\
\hline Hypertension, $\%(95 \% \mathrm{Cl})$ & $31.3(29.1-33.5)$ & $34.5(24.5-45.7)$ & $46.6(39.1-54.2)^{\dagger}$ & $52.3(48.3-56.4)^{\dagger \ddagger}$ \\
\hline Family history of Hypertension, $\%(95 \% \mathrm{Cl})$ & $10.5(9.0-11.9)$ & $13.1(6.7-22.2)$ & $10.8(6.6-16.3)$ & $21.1(17.8-24.4)^{\dagger \ddagger \Delta}$ \\
\hline Heart rate(beats/min) & $76(64-84)$ & $75(68-84)$ & $72(68-80)^{\dagger}$ & $72(68-80)^{\dagger}$ \\
\hline C-reactive protein $(\mathrm{mg} / \mathrm{L})^{*}$ & $5.5(3.7-10.5)$ & $7.4(4.3-15.1)^{\dagger}$ & $6.8(4.1-11.4)^{\dagger}$ & $7.0(4.6-13.7)^{\dagger}$ \\
\hline High C- reactive protein, $\%$ & $23.6(21.5-25.6)$ & $34.5(24.5-45.7)$ & $26.2(19.8-33.4)$ & $27.1(23.5-30.7)$ \\
\hline Fasting insulin $(\mu \mathrm{lU} / \mathrm{mL})^{*}$ & $12.1(8.9-14.9)$ & $12.5(10.3-16.1)$ & $11.6(8.3-15.1)$ & $11.9(8.4-15.3)$ \\
\hline
\end{tabular}

*: variables were described as median and quartile range;

$t$ : Compared to non drinking group, $\mathrm{P}<0.05$;

$\ddagger$ : Compared to drinkers with $\leq 25 \mathrm{~g} /$ day, $P<0.05$;

$\Delta$ : Compared to drinkers with $26-50 \mathrm{~g} /$ day, $\mathrm{P}<0.05$.

Table 1: Baseline characteristics of participants and comparisons according to different alcohol drinking status.

\begin{tabular}{|l|l|l|l|l|}
\hline \multirow{2}{*}{ alcohol drinking status } & \multicolumn{2}{|l|}{ Impaired fasting glucose $(n=149), \%$} & Diabetes $(n=94), \%$ \\
\cline { 2 - 5 } & Un-adjusted & Age-gender-adjusted & Un-adjusted \\
\hline Non-drinking $(n=1707)$ & $5.98(4.90-7.21)$ & $5.94(4.77-7.12)$ & $3.75(2.90-4.76)$ \\
\hline$\leq 25 \mathrm{~g} /$ day $(n=84)$ & $7.14(2.67-14.90)$ & $5.59(3.98-7.34)$ & $2.38(0.29-8.34)$ \\
\hline $26-50$ gay $(n=176)$ & $4.55(1.98-8.76)$ & $3.56(1.51-5.61)$ & $1.21(0.78-1.64)^{\dagger}$ & $0.57(0.01-3.12)$ \\
\hline$>50 \mathrm{day}(n=596)$ & $5.54(3.84-7.69)$ & $3.61(2.19-5.04)$ & $0.31(0.00-0.74)^{\dagger \ddagger}$ & \\
\hline
\end{tabular}

$t$ : Compared to non drinking group, $\mathrm{P}<0.05$;

¥: Compared to drinkers with $\leq 25 \mathrm{~g} /$ day, $P<0.05$;

$\triangle$ : Compared to drinkers with $26-50 \mathrm{~g} /$ day, $\mathrm{P}<0.05$

Table 2: Un-adjusted and age-gender-adjusted proportions of impaired fasting plasma glucose and diabetes according to alcohol drinking status. 
Citation: Li H, Wang G, Wang A, Tong W, Zhang Y (2011) Alcohol Consumption and Risk of Type 2 Diabetes in Mongolian Population, Inner Mongolia, China. J Diabetes Metab 2:116. doi:10.4172/2155-6156.1000116

Page 3 of 5

\begin{tabular}{|c|c|c|c|c|c|c|}
\hline \multirow{2}{*}{ alcohol drinking status } & \multicolumn{3}{|c|}{ Impaired fasting glucose } & \multicolumn{3}{|l|}{ Diabetes } \\
\hline & Un-adjusted & Age-gender- adjusted & Multivariate- adjusted" & Un-adjusted & Age-gender-adjusted & Multivariate- adjusted \\
\hline Non-drinking $(n=1707)$ & 1.00 (ref) & 1.00 (ref) & 1.00 (ref) & 1.00 (ref) & 1.00 (ref) & 1.00 (ref) \\
\hline$\leq 25 \mathrm{~g} /$ day $(n=84)$ & $1.19(0.51-2.80)$ & $1.07(0.45-2.56)$ & $1.07(0.44-2.59)$ & $0.63(0.15-2.64)$ & $0.52(0.12-2.19)$ & $0.47(0.11-2.11)$ \\
\hline $26-50 \mathrm{~g} /$ day $(n=176)$ & $0.72(0.35-1.51)$ & $0.66(0.31-1.40)$ & $0.68(0.31-1.47)$ & $0.14(0.02-1.05)$ & $0.12(0.02-0.88)^{\dagger}$ & $0.11(0.01-0.84)^{\dagger}$ \\
\hline$>50 \mathrm{~g} /$ day $(n=596)$ & $0.93(0.62-1.39)$ & $0.87(0.53-1.43)$ & $0.78(0.46-1.33)$ & $1.21(0.77-1.92)$ & $1.04(0.58-1.85)$ & $0.81(0.42-1.57)$ \\
\hline$P$ value for quadratic trend test & 0.756 & 0.614 & 0.803 & 0.027 & 0.018 & 0.026 \\
\hline
\end{tabular}

*: Adjustment factors include age, gender, smoking, hypertension, family history of hypertension, body mass index, waist circumference, heart rate, total cholesterol, triglycerides, HDL-cholesterol, LDL-cholesterol, c-reactive protein and fasting insulin.

$\dagger$ : Compared to non-drinking group, $\mathrm{P}<0.05$.

OR: Odds ratio; $\mathrm{Cl}$ : Confidence interval.

Table 3: ORs and $95 \% \mathrm{Cls}$ of impaired fasting plasma glucose and diabetes associated with alcohol consumption status.

test and significance level was 0.05 . Statistical analyses were conducted using SAS statistical software (version 9.1).

\section{Results}

Among 2589 participants, 26 subjects were excluded because of lack of FPG information, and 2563 subjects were finally included in the analysis. There were 94 subjects with diabetes and 149 subjects with IFG, and the prevalence of the diabetes and IFG were $3.7 \%$ (3.9\% in males and $3.5 \%$ in females) and 5.8\% (5.6\% in males and 6.0\% in females), respectively, among 2563 subjects. There were 1707 non-drinkers, 84 subjects drinking $\leq 25 \mathrm{~g}$ alcohol per day, 176 subjects drinking 26-50 g alcohol per day and 596 subjects drinking $>50 \mathrm{~g}$ alcohol per day among 2563 subjects.

(Table 1) presents the baseline characteristics according to alcohol drinking status. Compared to non-drinkers, subjects drinking $\leq 25$ $\mathrm{g}$ alcohol per day more likely to be older and smokers, had higher proportion of males and levels of SBP and CRP; subjects drinking 26$50 \mathrm{~g}$ alcohol per day were more likely to be older, males and smokers, had higher TG, SBP and DBP levels, higher rates of high TG and hypertension. Subjects drinking $>50 \mathrm{~g}$ alcohol per day also had older age, higher proportions of males and smokers, lower BMI level, lower rates of overweight and central obesity, higher TG and TC levels, higher rates of high TG and hypertension and family history of hypertension, higher SBP, DBP and CRP levels than non-drinkers. Moreover, subjects who drank more than $50 \mathrm{~g}$ alcohol per day had higher proportions of males and smokers, were more likey have a family history of hypertension, had higher TG level than subjects drinking $\leq 25 \mathrm{~g}$ alcohol per day. Moreover, compared to those drinking 26-50 g alcohol per day, they were more likely to have higher rates of males and smokers, higher TG level, higher rates of high TG and hypertension, higher rates of persons with family history of hypertension.

Un-adjusted and age-gender-adjusted rates of IFG and diabetes according to drinking status are listed in (Table 2) Although agegender-adjusted rates of IFG in drinkers were lower than that in non-drinkers, the differences among four groups were not significant $(\mathrm{p}=0.58)$. After adjusting for age and gender, the rates of diabetes were significantly lower in subjects drinking $\leq 25 \mathrm{~g}$ alcohol per day and 26-50 $\mathrm{g}$ alcohol per day than that in both non-drinker and subjects drinking $>50 \mathrm{~g}$ alcohol per day.

Associations between alcohol drinking and IFG and diabetes are presented in (Table 3). Compared to non-drinker, those drinking 26$50 \mathrm{~g}$ alcohol per day had significantly lower risk of diabetes adjusted for age and gender $(\mathrm{OR}=0.12,95 \% \mathrm{CI}, 0.02-0.88)$, it remained significant after multivariate adjustment, however, alcohol consumption $>50 \mathrm{~g}$ alcohol per day was not significantly associated with diabetes no matter adjusting for age and gender or multivariate. There was not significant association between alcohol consumption and IFG after adjusting for age and gender or multivariate.

\section{Discussion}

Our study found there was a quadratic curve (U- shaped) relationship between alcohol drinking and diabetes, and alcohol consumption of 26-50 g per day was inversely associated with risk of type 2 diabetes, compared to non-drinking group, while drinking $>50$ g alcohol per day was not associated with type 2 diabetes, which appeared to indicate that proper quantities of alcohol consumption may be a protective factor for type 2 diabetes. This finding was consistent with other studies $[18,19]$ showing that proper quantities of alcohol consumption was associated with decreased risk of type 2 diabetes. A study [18] showed that there was a U-shaped relationship between alcohol consumption and the incidence of IFG or type 2 diabetes in middle-aged Japanese men, with the lowest incidence at alcohol intake of 23.0-45.9 $\mathrm{g}$ alcohol per day. The finding was much similar to our study, in which drinking 26-50 g alcohol per day appeared to be the most suitable quantities for prevention of type 2 diabetes. Djousse et al. [19] studied prospectively 4655 participants who were free of diabetes at baseline, they found that light to moderate alcohol consumption ( $<7$ drinks/week, 1 drink=12.5 g alcohol) was associated with a lower incidence of type 2 diabetes among elderly people, irrespective of the type of beverage consumed. Some meta-analysis [20-22] also found a $\mathrm{U}$-shaped relationship between alcohol consumption per day and type 2 diabetes. Carlsson and colleagues [20] conducted a meta-analysis for the findings of 13 studies, they found that moderate alcohol consumption (approximately 5-30 g of alcohol per day) has protective effect on type 2 diabetes (relative risk(RR) ${ }_{\text {meta }}=0.72,95 \% \mathrm{CI}, 0.67-0.77$ ). Baliunas's meta-analysis [21] including 20 cohort studies revealed that the risk of type 2 diabetes was lowest among men who drank $22 \mathrm{~g}$ alcohol per day $(\mathrm{RR}=0.87,95 \% \mathrm{CI}, 0.76-1.00)$, among women who drank $24 \mathrm{~g}$ alcohol per day $(\mathrm{RR}=0.60,95 \% \mathrm{CI}, 0.52-0.69)$. A meta-analysis [22] including 15 cohort study was undertaken by Koppes et al. [22] which found that the RRs for type 2 diabetes in those who consumed $\leq 6,6-12,12-24$, $24-48, \geq 48 \mathrm{~g}$ acohol per day were $0.87(95 \% \mathrm{CI}, 0.79-0.95), 0.70(0.61-$ $0.79), 0.69(0.58-0.81), 0.72(0.62-0.84)$ and $1.04(0.84-1.29)$, respectively, compared with nondrinkers.

Conigrave `s study showed that [7] consumption of 15-29 g alcohol per day was associated with a lower risk of diabetes (RR 0.64; 95\% CI, 0.53-0.77), compared with non alcohol consumption; and there was a significant inverse association between heavy drinkers (drinking $\geq 50 \mathrm{~g}$ alcohol per day) and type 2 diabetes ( $R R=0.60$, 95\%CI 0.43-0.8) among health professional males in United States. However, Holbrook et al. [11] followed 524 American adults for 12 years in a general community, their findings showed that drinking $25 \mathrm{~g}$ alcohol per day significantly increase incidence of type 2 diabetes among men but not among women. In the present study, drinking 26-50 g alcohol per day decreased the risk of type 2 diabetes, we did not find a significant association of drinking $>50 \mathrm{~g}$ alcohol per day with type 2 diabetes. The differences in rate of IFG among four groups were not statistically significant, though the rate of IFG in drinkers were lower than that in non-drinkers. 
Some epidemiologic studies [23-25] have showed that proper quantities of alcohol consumption was a protective factor for coronary heart disease. Mechanisms of protective effect of proper quantities of alcohol consumption on type 2 diabetes may be the same as on coronary heart disease. This protective effect on type 2 diabetes or coronary heart disease may be explained by a viewpoint that moderate alcohol consumption can increase insulin sensitivity and high HDL-C [26-31]. For example, Rimm et al. [26] reported that an experimental dose of 30 $\mathrm{g}$ of ethanol a day increased concentrations of HDL-C by $3.99 \mathrm{mg} / \mathrm{dl}$. Davies et al. [28] conducted a randomized controlled trial of 63 healthy postmenopausal women between 1998 and 1999, participants were randomly assigned to consume 0,15 , or $30 \mathrm{~g}$ alcohol per day for 8 weeks each as part of a controlled diet, their findings showed that consumption of $30 \mathrm{~g}$ alcohol per day reduced fasting insulin concentration by $19.2 \%$ $(\mathrm{P}=0.004)$ and triglyceride concentration by $10.3 \%(\mathrm{P}=0.001)$, and increased insulin sensitivity by $7.2 \%(\mathrm{P}=0.002)$ compared with non drinkers. In discussing relationship between alcohol drinking and diabetes, we need to discuss relationship between alcohol drinking and hypertension and cardiovascular disease. Hypertension is a confirmed cardiovascular disease associated with alcohol drinking. Klatsky [32] did a review for 70 studies from various countries, the studies solidly established an empiric relationship between heavy alcohol drinking ( $>/=3$ standard drinks/day) and hypertension. In another review, Lip et al. [33] concluded that there was probably a causal relationship between heavy alcohol drinking and hypertension, moderate alcohol drinking had a protective effect on cardiovascular system. Our findings also indicated that moderate alcohol drinking had a protective effect on type 2 diabetes. However, it needs to be elucidated that definite quantity of moderate alcohol drinking for protective effects on diabetes may be different from that for protective effects on hypertension.

There are some limitations in the present study. Firstly, in the cross-sectional study, alcohol information was self-reported. Secondly, we only examined FPG, and did not examine $2 \mathrm{~h}$ plasma glucose after meal which may lead to underestimate the rates of diabetes among the Mongolian people, and we did not investigate the diet and status of physical activity that could confound the results in the present study. Thirdly, approximately $25 \%$ of the eligible population from these villages chose not participate which may have introduced some selection bias. However, we believe that this bias is minimal because participants who chose not participate did not know their blood glucose levels. There were several important strengths of our study that also deserve mention. The study participants, the Mongolians, were homogeneous regarding their genetic background, environmental exposures and lifestyles. The study data were collected with rigid quality control and important covariables were measured and controlled in the analysis.

In summary, the inverse association between proper quantities of alcohol consumption and type 2 iabetes was found in our study. However, the relationship between alcohol consumption and diabetes is more complex, and mechanism of how light or moderate alcohol intake decrease the risk of diabetes remains to be further studied in the future.

\section{Conflict of Interest}

The authors declare that they have no conflict of interest.

\section{Acknowledgements}

We are deeply appreciative of the participants in the study, and thank Kezuohouqi Banner Center for Disease Prevention and Control and Naiman Banner Center for Disease Prevention and Control for their support and assistance.

This study was supported by National Natural Science Foundation of China (Grant No. 30471484)

\section{References}

1. Taylor B, Irving HM, Baliunas D, Roerecke M, Patra J, et al. (2009) Alcohol and hypertension: gender differences in dose-response relationships determined through systematic review and meta-analysis. Addiction 104: 1981-1990.

2. Sesso HD, Cook NR, Buring JE, Manson JE, Gaziano M (2008) Alcoho Consumption and the Risk of Hypertension in Women and Men. Hypertension 51: $1080-1087$

3. Reynolds K, Lewis B, Nolen JD, Kinney GL, Sathya B, et al. (2003) Alcohol consumption and risk of stroke: a meta-analysis. JAMA 289: 579-588.

4. Ikehara S, Iso H, Toyoshima H, Date C, Yamamoto A, et al. (2008) Alcohol consumption and mortality from stroke and coronary heart disease among Japanese men and Women : the Japan collaborative cohort study. Stroke 39 : 2936-2942.

5. Ajani UA, Hennekens $\mathrm{CH}$, Spelsberg A, Manson JE (2000) Alcohol consumption and risk of type 2 diabetes mellitus among US male physicians. Arch Intern Med 160: 1025-1030.

6. Tsumara K, Hayashi T, Suetmatsu C, Endo G, Fujii S, et al. (1999) Daily alcohol consumption and the risk of type 2 diabetes in Japanese men. Diabetes Care 22: $1432-1437$

7. Conigrave KM, Frank Hu B, Camargo Jr. CA, Stampfer MJ, Willett WC, et al. (2001) A prospective study of drinking patterns in relation to risk of type 2 diabetes among men. Diabetes 50: 2390-2395.

8. Feskens EJM, Kromhout D (1989) Cardiovascular risk factors and the 25-yea incidence of diabetes mellitus in middle-aged men. Am J Epidemiol 130: 1101 1108.

9. Hodge AM, Dowse GK, Collins VR (1993) Abnormal glucose tolerance and alcohol consumption in three populations at high risk of non-insulin-dependent diabetes mellitus. Am J Epidemiol 137: 178-189.

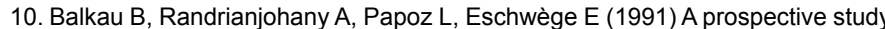
of alcohol use and non-insulin-dependent diabetes mellitus. Am J Epidemiol 134: $1469-1470$.

11. Holbrook TL, Barrett-Connor E, Wingard DL (1990) A prospective populationbased study of alcohol use and non-insulin-dependent diabetes mellitus. Am J Epidemiol 132: 902-909.

12. Gu D, Reynolds K, Duan X, Xin X, Chen J, et al. (2003) Prevalence of diabetes and impaired fasting glucose in the Chinese adult population: International Collaborative Study of Cardiovascular Disease in Asia (InterASIA). Diabetologia 46: 1190-1198

13. Yang W, Lu J, Weng J, Jia W, Ji L, et al. (2010) Prevalence of diabetes among men and women in China. New Engl J Med 362: 1090-101.

14. Li H, Xu T, Tong W, Liu Y, Zhao L, et al. (2008) Comparison of Cardiovascular Risk Factors Between Prehypertension and Hypertension in a Mongolian Population, Inner Mongolia, China. Circ J 72: 1666-1673.

15. Zhou (2002) Predictive values of body mass index and waist circumference to risk factors of related diseases in Chinese adult population. Zhonghua Liu Xing Bing Xue Za Zhi 23: 5-10.

16. Chinese Diabetes Society (2008) China Guideline for Type 2 Diabetes (2007 Edition). Natl Med J China88: 1227-1245.

17. Friedewald WT, Levy RI, Fredrickson DS (1972) Estimation of the concentration of low-density lipoprotein cholesterol in plasma, without use of the preparative ultracentrifuge. Clin Chem 18: 499-502.

18. Nakanishi N, Suzuki K, Tatara K (2003) Alcohol consumption and risk fo development of impaired fasting glucose or type 2 diabetes in middle-aged Japanese men. Diabetes Care 26: 48-54.

19. Djousse L, Biggs ML, Mukamal KJ, Siscovick DS (2007) Alcohol consumption and type 2 diabetes among older adults: The Cardiovascular Health Study. Obesity 15: 1758-1765

20. Carlsson S, Hammar N, Grill V (2005) Alcohol consumption and type 2 diabetes Meta-analysis of epidemiological studies indicates a U-shaped relationship. Diabetologia 48: 1051-1054.

21. Baliunas DO, Taylor BJ, Irving H, Roerecke M, Patra J, et al. (2009) Alcohol as a risk factor for type 2 diabetes. Diabetes Care 32: 2123-2132. 
Citation: Li H, Wang G, Wang A, Tong W, Zhang Y (2011) Alcohol Consumption and Risk of Type 2 Diabetes in Mongolian Population, Inner Mongolia, China. J Diabetes Metab 2:116. doi:10.4172/2155-6156.1000116

Page 5 of 5

22. Koppes LL, Dekkep JM, Hendriks HF, Bouter LM, Heine RJ (2005) Moderate alcohol consumption lower the risk of type 2 diabetes: a meta-analysis of prospective observational studies. Diabetes Care 28: 719-725.

23. Hvidtfeldt UA, Tolstrup JS, Jakobsen MU, Heitmann BL, Grønbæk M, et al. (2010) Alcohol intake and risk of coronary heart disease in younger, middleaged, and older adults. Circulation 121: 1589-1597.

24. Mukamal KJ, Chiuve SE, Rimm EB (2006) Alcohol consumption and risk for coronary heart disease in men with healthy lifestyles. Arch Intern Med 166: 2145-2150.

25. Shaper AG, Wannamethee G, Walker M (1994) Alcohol and Coronary Heart Disease: A Perspective from the British Regional Heart Study. Int J Epidemiol 23: $482-494$

26. Rimm EB, Williams P, Fosher K, Criqui M, Stampfer MJ (1999) Moderate alcohol intake and lower risk of coronary heart disease: metaanalysis of effects on lipids and haemostatic factors. BMJ 319: 1523-1528.

27. Mayer EJ, Newman B, Quesenberry CP Jr, Friedman GD, Selby JV (1993) Alcohol consumption and insulin concentrations: role of insulin in associationso alcohol intake with high-density lipoprotein cholesterol and triglycerides. Circulation 88: 2190-2197.
28. Davies MJ, Baer DJ, Judd JT, Brown ED, Campbell WS, et al. (2002) Effects of moderate alcohol intake on fasting insulin and glucose concentrations and insulin sensitivity in postmenopausal women: a randomized controlled trial. JAMA 287: 2559-2562.

29. Sierksma A, Patel H, Ouchi N, Kihara S, Funahashi T, et al. (2004) Effect of moderate alcohol consumption on adiponectin, tumor necrosis factor-alpha, and insulin sensitivity. Diabetes Care 27: 184-89.

30. Kiechl S, Willeit J, Poewe W, Egger G, Oberhollenzer F, et al. (1996) Insulin sensitivity and regular alcohol consumption: large, prospective, cross-sectional population study (Bruneckstudy). BMJ 313:1040-1044.

31. Facchini F, Chen YD, Reaven GM (1994) Light-to-moderate alcohol intake is associated with enhanced insulin sensitivity. Diabetes Care 17: 115-119.

32. Klatsky AL (2003) Alcohol and cardiovascular disease--more than one paradox to consider. Alcohol and hypertension: does it matter? Yes. J Cardiovasc Risk10: 21-24.

33. Lip GY, Beevers DG (2003) Alcohol and cardiovascular disease--more than one paradox to consider. Alcohol and hypertension--does it matter? (no!). J Cardiovasc Risk 10: 11-14. 